\title{
Personal Pronouns Study in Analects of Confucius
}

\author{
Lirong $\mathrm{Xiao}^{1, \text { a }}$ \\ ${ }^{1}$ College of Literature and Journalism, Sichuan University, Chengdu, Sichuan Province, China \\ a835354630@qq.com
}

Keywords: Analects of Confucius; personal pronouns, syntactic functions, addressees, singular and plural forms .

\begin{abstract}
Combined mathematical statistics, this paper investigates the personal pronouns' syntactic functions, addressees, singular and plural forms in Analects of Confucius.
\end{abstract}

\section{Introduction}

It is of great significance to explore the usage of personal pronouns in Analects of Confucius, the paradigm of quotation prose.

\section{First Person Pronouns}

There is an indefinite pronoun huo ( someone) appears for 15 times in the book, of which 13 times refer to people and are used as the subject in both singular and plural forms. For example, Someone addressed Confucius, saying, "sir, why are you not engaged in the government?" The word is not included in this article since it does not refer to certain persons.

$\boldsymbol{W u} . W u(\mathrm{I} / \mathrm{us})$ is used as a first person pronoun in the book. It appears in the text for 113 times, of which 95 times are employed as the subject. For example, $I$ have heard that the superior man is not a partisan. May the superior man be a partisan also? (Chapter 7)

$W u$ is employed as the object for 3 times, and in all the cases the word serves as the prepositional object in negative sentences. For instance, If there had been government business, though $I$ am not now in office, I should have been consulted about it. (Chapter 13)

$W u$ is utilized as the attribute for 14 times. For example, Formerly $I$ had a friend who pursued this style of conduct. (Chapter 5)

It is used as the appositive for 1 time, in which $w u$ collocates with the appositive, and is used as the subject. That is, Zan yu said, "Our master wishes the thing; neither of $u s$ two ministers wishes it." (Chapter 16)

Wo. Wo (I/us) occurs for 46 times. It refers to first person in 45 cases, of which 18 times are utilized as the subject. For example, $I$ have not seen the case in which his strength would be insufficient. (Chapter 4)

$W o$ is used as the object of verbs for 16 times. For instance, Does the high officer know me? (Chapter 9)

It is employed as the object of prepositions for 7 times. For example, The silent treasuring up of knowledge; learning without satiety; and instructing others without being wearied: which one of these things belongs to $m e$ ? (Chapter 7)

$W o$ is served as the prepositional object in negative sentences for 2 times; such as, There is no one that knows me! (Chapter 14)

It is used as the indirect object in double-objects sentence for 1 time. That is:

A transmitter and not a maker, believing in and loving the ancients, venture to compare myself with our old P'ang (Chapter 7)

It is employed as the attribut for 1 time, namely:

When I walk along with two others, they may serve me as my teachers (Chapter 7)

$\boldsymbol{Y} \boldsymbol{u} . Y u(\mathrm{I})$ is used as a first person pronoun in the book. It appears 23 times, in which 11 times are utilized as the subject. For example, And though I may not get a great burial, shall $I$ die upon the road? (Chapter 9) 
$Y u$ is used as the object of verbs for 5 times. For instance,

Hui behaved towards me as his father. I have not been able to treat him as my son (Chapter 11)

$Y u$ serves as the object of prepositions for 4 times; such as,

While Heaven does not let the cause of truth perish, what can the people of K'wang do to me? (Chapter 9)

It is served as the prepositional object in negative sentence for 1 time. That is, I have no pleasure in being a prince, but only in that no one can offer any opposition to what $I$ say! (Chapter 13)

$Y u$ is employed as the attribute for 2 times. For example, The philosopher Tsang being ill, he cared to him the disciples of his school, and said, "Uncover my feet! Uncover my hands!" (Chapter 8)

Zhen. Zhen (I) appears for 2 times, and all serve as the attribute, such as $I$ commit offenses; they are not to be attributed to you, the people of the myriad regions. If you in the myriad regions commit offenses, these offenses must rest on my person. (Chapter 20)

Comparative study of $\boldsymbol{w u}, \boldsymbol{w o}, \boldsymbol{y} \boldsymbol{u}$ and $\boldsymbol{z h e n . ~ S y n t a c t i c ~ f u n c t i o n s . ~} W u$ is more frequently used as the subject or the attribute; it can also be employed as the object or the appositive. Wo is more commonly used as the subject or the object; it can also be utilized as the attribute. $Y u$ is more commonly employed as the subject or the object; it can also be served as the attribute. Zhen is used as the attribute in all cases.

When the word is used as the object, wo appears more frequently than $y u$ and $w u$. $Y u$ cannot occur in double-objects expressions. $W u$ can be used as the prepositional object only when it cooperate with negative words like $w u$ (no) or $b u$ (no). Wo can be employed as the object of verbs, or the object of prepositions; it can also be used in negative sentences as the prepositional object, or serves as the direct object in double-objects expressions. The difference can be found clearly when $w u$ and $w o$ occur at the same time. For instance, Hui gives me no assistance. There is nothing that $I$ say in which he does not delight. (Chapter 11)

When the word is employed as the attribute, $w u$ is more frequently used than $y u$ zhen and $w o$. In the book Analects of Confucius, zhen refers to the speaker when it is used as the attribute; wo expresses affection when it is utilized as the attribute. $Y u$ and $w u$ do not have similar meanings. They refer to speaker's body parts or things closely related to the speaker. For example, The philosopher Tsang being ill, he cared to him the disciples of his school, and said, "Uncover $m y$ feet! Uncover $m y$ hands!" (Chapter 8)

The philosopher Tsang said, "I daily examine myself on three points." (Chapter 1)

Having exerted all my ability, there seems something to stand right up before me. (Chapter 9)

Singular and plural forms (In ancient Chinese language, there is no clear boundary between the singular and plural pronouns. We need do tell them according to the antecedents.)

In the book Analects of Confucius, wu appears in both singular and plural forms. (There are three cases that the expression cannot be defined as singular or plural form. 1)The little children of $m y$ school are ambitious and too hasty. They are accomplished and complete so far, but they do not know how to restrict and shape themselves.(Chapter 5) 2) Confucius said, "among us, in our part of the country, those who are upright are different from this." (Chapter 13) 3) The duke of Sheh informed Confucius, saying, "Among $u$ s here there are those who may be styled upright in their conduct. If their father has stolen a sheep, they will bear witness to the fact." (Chapter 13) It is used in singular forms for 3 times. For instance,

The Master said, "He is no disciple of mine. My little children beat the drum and assail him." (Chapter 11)

It is employed in plural pronouns for 3 times, too. For example, Coming to another state, he said, "They are here like our great officer." (Chapter 5)

Wo only appears in singular forms. It may be related to the quotation form of the book, since most of the conversations are carried out between two parties. For example, The Master said, "Ts'ze, you love the sheep; I love the ceremony." (Chapter 3)

$Y u$ is only used in singular forms, because it refers to the speaker. For instance, And though $I$ may not get a great burial, shall $I$ die upon the road? (Chapter 9)

Zhen is used only in singular forms, too. The emperor used this word to call himself. 
Addressees. Basically, $w u$ and $w o$ have same addressees. The usage of $y u$ is relatively simple. $W u$ appears for 113 times in quotations, of which 54 cases do not mention the speakers or the relationship between speakers. In other case, the word is used for 6 times by superiors to address inferiors. For example, "With two tenths", said the duke, "I find it not enough; how could I do with that system of one tenth?" (Chapter 12)

$W u$ is used by inferiors to address superiors for 12 times. For instance, Confucius said, "Right; $I$ will go into office" (Chapter 17)

$W u$ is employed by teachers to address students for 33 times, include He said to them, "Though $I$ am a day or so older than you, $I$ do not think of that." (Chapter 11)

It is utilized by students to address teachers for 6 times. For example, "Our master wishes the thing; neither of us two ministers wishes it." (Chapter 16)

$W u$ is used between classmates for 2 times. For instance, Fan Ch'ih retired, and, seeing Tsze-hsia, he said to him, "a little while ago, I had an interview with our master, and asked him about knowledge. (Chapter 12)

Wo appears for 46 times, of which 15 times do not mention the relationship between speakers. In other cases, the word is utilized 19 times by the teacher to address students; for instance, The Master said to Yen Yuan, "When called to office, to undertake its duties; when not so called, to he retired; it is only $I$ and you who have attained to this." (Chapter 7)

Wo is used by students to address teachers for 4 times; for example, The Master, by orderly method, skillfully leads men on. He enlarged my mind with learning, and taught me the restraints of propriety. When I wish to give over the study of his doctrines, I cannot do so. (Chapter 9)

It is employed by superiors to address inferiors for 4 times. For instance, But if a mean person, who appears quite empty-like, ask anything of me. (Chapter 9)

Wo is used by inferiors to address superiors for 2 times, such as, The Master heard of the conversation and said, "Does the high officer know me?" (Chapter 9)

It is utilized between classmates for one time. That is, Sze-ma Niu, full of anxiety, said, "All other men have their brothers; I have none." (Chapter 12)

For the above analysis, it can be found that there is no clear boundary between the usage of $w u$ and wo . Both of them can be used by the speaker to address students, superiors, teachers, inferiors and classmates.

Another first person pronoun, $y u$, can be used only by superiors or teachers to address their inferiors or students. The word appears in Analects of Confucius for 23 times, of which 3 quotations do not mention the relationship between speakers; 2 quotations are references. It is used by the emperor to call himself for 2 times. In other cases, 15 times are used by the teacher to address students. For instance, The Master said, "It is Shang who can bring out my meaning. Now I can begin to talk about the odes with him." (Chapter 3)

$Y u$ is used by superiors to address inferiors for 1 time, that is, Yang ho said to Confucius, "come, let me speak with you." (Chapter 17)

$Y u$ is employed in references for 2 times. For example, There is a saying among men: " $I$ have no pleasure in being a prince; but only in that no one can offer any opposition to what $I$ say!" (Chapter 13)

\section{Second Person Pronouns}

$\boldsymbol{E r}^{\mathbf{l}} . \operatorname{Er}$ (you) appears in the book for 28 times, in which 21 times refers to second person. In these cases, It is used as the subject for 8 times, include, "Ch'iu, what are your wishes?" (Chapter 11)

$E r$ serves as the object of verbs for 3 times. For example, If some ruler were to know you, what would you like to do? (Chapter 11)

$E r$ is employed as the object of prepositions for 3 times. For instance, Ho said to Confucius, "let me speak with you." (Chapter 17)

It is utilized as the prepositional object in negative sentence for 1 time, that is, Do I not think of you? But your house is distant. (Chapter 9) 
Er is used as the attribute for 5 times, include, The Master said, "Come, let each of you tell his wishes." (Chapter 5)

$E r$ is served as the appositive for 1 time. That is, Yao said, "Oh! You, Shun, the heaven-determined order of succession now rests in your person." (Chapter 20)

$\boldsymbol{R} \boldsymbol{u} . R u$ (you) is used as a second person pronoun in the book for 17 times, of which 13 times are employed as the subject. For example, The Master said to Tsze-kung, "Which do you consider superior, yourself or Hui?" (Chapter 5)

$R u$ serves as the object of verbs for 3 times. For instance, The Master said, "Yu, shall I teach you what knowledge is?" (Chapter 2)

$R u$ is employed as the object of prepositions for 1 time. That is, The master said, "If you were, after a year, to eat good rice, and wear embroidered clothes, would you feel at ease?" (Chapter 17)

$\boldsymbol{E r}^{2}$. Er (you) occurs in the book for 319 times, while only 1 time is used as personal pronouns. In that case the word refers to second person, and is used as the subject. That is, Rather than follow one who merely withdraws from this one and that one, had you not better follow those who have withdrawn from the world altogether? (Chapter 18)

Comparative study of $e r, r u$ and $e r$. Syntactic functions. $E r^{1}$ is more frequently used as the subject or the object; it can also be employed as the attribute or the appositive. $R u$ is more commonly used as the subject or the object. $E r^{2}$ can only be utilized as the subject.

Ch'iu! Is it not you who are in fault here? (Chapter 16)

The Master said, "Ts'ze, you think, I suppose, that I am one who learns many things and keeps them in memory?" (Chapter 15)

The Master said, "I thought you had died." (Chapter 11)

Addressees. $E r^{l}$ is used to quote what the ancient said for two times. In other cases, it is employed by the teacher to address his students for 16 times. For example, The Master said, "Ts'ze, you have not attained to that." (Chapter 5)

It is used by superiors to address inferiors for 3 times. For example, Ho said to Confucius, "come, let me speak with you." (Chapter 17)

It is utilized to quote what the ancient said for 2 times. For instance, We performed rites of expiation for you, calling upon the sky-spirits above and the earth-spirits below. (Chapter 7)

$R u$ is used by the teacher to address students in all cases, such as:

The Master said, "Yu, shall I teach you what knowledge is?" (Chapter 2)

Singular and plural forms. $E r^{l}$ can be used to in both singular and plural forms. It is used in singular form for 18 times. For instance, The Master said, "Ts'ze, you love the sheep; I love the ceremony." (Chapter 3)

It is employed in plural forms for 3 times, include:

The Master said to them, "Come, let each of you tell your wishes." (Chapter 5)

$R u$ can be used in singular forms only. For instance, The Master said to Tsze-kung, "Which do you consider superior, yourself or Hui?" (Chapter 5)

$E r^{2}$ can only be utilized in singular forms. It refers to Tsze-lu.

Collocation of first person and second person pronouns. When first person and second person pronouns are used in one quotation, $e r^{l}$ can be utilized together with $w u$, wo and $y u$. For instance,

The Master said, "Ts'ze, you love the sheep; I love the ceremony."(Chapter 3)

"Though I am a day or so older than you, I do not think of that. (Chapter 11)

Ho said to Confucius, "come, let me speak with you." (Chapter 17)

$R u$ can be employed together with $w u$ and $y u$. For example, The Master said, "I thought you had died." (Chapter 11)

The master said, "Ts'ze, you think that $I$ am one who learns many things and keeps them in memory?" (Chapter 15)

$E r^{2}$ cannot be used together with first person pronouns. 


\section{Third Person Pronouns}

Zhi. Zhi (he/she/they) appears for 596 times, of which 290 times are used as personal pronouns, 140 times refer to persons, 150 times refer to things. In these cases, it is used as the object of verbs for 271 times. For example, When the bearer of this message went out at the door, the master took his lute and sang to it, in order that he might hear him. (Chapter 17)

Zhi is employed as the indirect object in double-objects expressions for 11 times. For instance, Yuan Sze being made governor of his town by the Master, he gave him nine hundred measures of grain, but Sze declined them. (Chapter 6)

It is utilized as the prepositional object in negative sentences for 6 times. For example, If a ruler's words be good, is it not also good that no one oppose them? (Chapter 13)

It is used as the attribute for 2 times. For example, The viscount of Wei withdrew from the court. The viscount of Chi became a slave to him. (Chapter 18)

Qi. $Q i$ (he/she/they) occurs for 254 times, of which 173 times are used as personal pronouns. It refers to persons for 143 times, refers to things for 30 times. In these cases, the word is used as the attribute for 130 times. For example, The Master said, "While a man's father is alive, look at the bent of his will; when his father is dead, look at his conduct. If for three years he does not alter from the way of his father, he may be called filial." (Chapter 1)

It is employed as the subject (It has been widely accepted that $q i$ can serves as the attributive when it is used as a pronoun. However, it's still a controversial issue that whether the word can be employed as the subject. Jian-zhong Ma (1983:50) believes that it can be used as the subject, particularly the subject in the subject-predicate phrases. Li Wang (1982:85) believes that the meaning of $q i$ is equal to "the noun plus zhi". In ancient Chinese, it takes the front position and the previous statements are wrong. He cites many examples to prove this point of view. For example, The Master said of Yen Yuan, "Alas! I saw his constant advance. I never saw him stop in his progress." Shu-xiang Lv basically agrees will Li Wang, and holds that $z h i$ and $q i$ are used to transform sentences into phrases. For example, I wish you allow us to engage in war; if you do not allow it, we will be engage in war anyway. (Zuo Zhuan) We believe that qi can be used as the subjects of the whole sentences. ) for 25 times. For instance, When he was in the prince's ancestral temple, or in the court, he spoke minutely on every point, but cautiously. (Chapter 10)

It is utilized as the object for 18 times, such as the Master said, "See what a man does. Mark his motives. Examine in what things he rests." (Chapter 2)

Bi. Bi (he/she) appears for only 3 times, of which 2 times are used as third person pronouns, and serve as the subject. For example, He asked about Tsze-hsi. The master said, "That man! That man!" (Chapter 14)

$\boldsymbol{F u}$. $F u$ (he/she) occurs for 44 times, but it is used as a third person pronoun for only one time. It serves as the subject in that case. That is, The master said, "May not Shun be instanced as having governed efficiently without exertion? What did he do? He did nothing but gravely and reverently occupy his royal seat." (Chapter 15)

Comparative Study of $\boldsymbol{z} \boldsymbol{h i}, \boldsymbol{q} \boldsymbol{i}, \boldsymbol{b i}$ and $\boldsymbol{f} \boldsymbol{u}$. Syntactic function. Zhi is more frequently used as the object; it can also be employed as the attribute or the subject. $Q i$ is more commonly used as the attribute, it can also be used as the subject or the object. $F u$ and $b i$ can only be utilized as the subject.

Referring different persons. Zhi and $q i$ can serve as the first, second and third person pronouns. When $z h i$ is used as the object, it can refer to the first, second and third persons, and create special language effects. It is used as the first person pronouns for 4 times. For example, Master swore, saying, "Wherein I have done improperly, may Heaven reject me, may Heaven reject me!" (Chapter 6)

It is employed as second person pronouns for 3 times. For instance, The duke Ching of Ch'i, with reference to the manner in which he should treat Confucius, said, "I cannot treat him as I would the chief of the Chi family. I will treat him in a manner between that accorded to the chief of the Chi and that given to the chief of the Mang family."(Chapter 18)

$Q i$ refers to first person for 4 times. For instance, 
Am I devoid of talents and virtue? Men will put me away from them. What have we to do with the putting away of others? (Chapter 19)

It refers to second person for 3 times. For example,

The master said, "When a prince's personal conduct is correct, his government is effective without the issuing of orders. If his personal conduct is not correct, he may issue orders, but they will not be followed." (Chapter 13)

$B i$ and $f u$ can only refer third person. $B i$ refers to Tsze-his, while $f u$ refers to Shun.

Singular and plural forms. Zhi and qi can be used in singular and plural forms; the following two quotations are singular forms;

When Yen Yuan died, the disciples wished to give him a great funeral. (Chapter 11)

He has retired, and I have examined his conduct when away from me, and found him able to illustrate my teachings. Hui! He is not stupid. (Chapter 2) the following two quotations are plural forms.

Po-I and Shu-ch'i died of hunger at the foot of the Shau-yang Mountains, and the people, down to the present time, praise them. (Chapter 16)

The mechanic, who wishes to do his work well, must first sharpen his tools. (Chapter 15)

$B i$ and $f u$ can only serve in singular forms.

To sum up, the first and second person pronouns in the Analects of Confucius are more complex, while the third person pronouns are relatively simple.

\section{References}

[1] Y. He, B. Xing, The Notes and Commentaries of the Analects of Confucius, Shanghai Classics Publishing House, Shanghai, 1990

[2] L. Wang, Chinese Language History Draft, The Chinese Publishing House, Beijing, 2008

[3] X. Xiang, A Concise History of Chinese Language, revised edition, The Commercial Press, Beijing, 2010

[4] Y. Li, A historical investigation of Chinese personal pronouns in plural forms, J. Guangxi Social Sciences. 9 (2003).

[5] Z.W. Yao, The expressions of third person pronouns in ancient Chinese language and related issues, J. Research in Ancient Chinese Language. 4 (2001).

[6] Z.M. Chen, The similarities and differences of the pronouns zhi and qi , J. Journal of Shanxi Normal University. 2 (2004).

[7] G.H Liang, The third person pronoun bi in ancient Chinese language, J. Guizhou Historical Studies. 2 (2004). 